\title{
Su kayıp yönetimi için temel hesaplama araçlarının geliştirilmesi ve temel su kayıp bileşenlerinin analizi
}

\author{
Development of basic analysis tools for water loss management and analysis of basic water \\ loss components
}

\author{
Mahmut FIRAT ${ }^{* 1, a}$, Salih YILMAZ ${ }^{2, b}$, Cansu BOZKURT ${ }^{3, c}$ \\ 'İnönü Üniversitesi, Mühendislik Fakültesi, İnşaat Mühendisliği Bölümü, 44250, Malatya \\ ${ }^{2}$ Malatya Su ve Kanalizasyon İdaresi Genel Müdürlüğ̈̈, Malatya \\ ${ }^{3}$ Ardahan Üniversitesi Teknik Bilimler Meslek Yüksek Okulu, Ardahan
}

• Geliş tarihi / Received: 19.10.2020 • Düzeltilerek geliş tarihi / Received in revised form: 18.02.2021 • Kabul tarihi / Accepted: 28.02 .2021

\section{$\ddot{O} \mathbf{z}$}

Su kayıp yönetimi, çeşitli yöntem ve süreçleri içermekte ve bu yöntemlerin kullanılması ile sürdürülebilir kentsel su yönetiminin sağlanması mümkün olmaktadır. Su ve enerji verimliliği ve sürdürülebilir su kayıp yönetiminde en uygun hesaplama araçlarının kullanılması ve uluslararası literatüre göre analiz yapılması önemlidir. Bu çalışmada, su kayıp yönetiminin sistematik, planlı ve sürdürülebilir bir şekilde yapılmasına esas teşkil eden temel su kayıp analizleri için hassas ve doğru analiz imkanı sunan hesaplama araçlarının geliştirilmesi amaçlanmıştır. Bunun için web tabanlı çalışan, birbiri ile bütünleşik olan "su dengesi”, "minimum gece debisi” ve "altyapı kaçak indeksi”" hesaplama araçları geliştirilmiş ve pilot veri seti için uygulama gerçekleştirilmiştir. Bu hesaplama araçlarının, İdarelerde, sızıntıların yönetilmesinde, su kayıp yönetim performanslarının izlenmesinde, sistem verimliliğinin sağlanmasında, sızıntı hesaplarının daha sistematik ve hassas bir şekilde yapılmasında, su kayıp yönetimi hesaplamalarının uluslararası standartlara göre yapılmasında önemli katkılar sunacağı düşünülmektedir.

Anahtar kelimeler: Hesaplama aracı, İçmesuyu dağıtım sistemi, Su dengesi, Su kayıpları, Su kayıp yönetimi

\begin{abstract}
Water loss management includes various methods and processes, and it is possible to ensure sustainable urban water management to use these methods. However, it is important to use the most appropriate tools and to analyze according to international literature in water and energy efficiency and sustainable water loss management. In this study, it is aimed to perform basic water loss analysis, which is the basis for systematic, planned and sustainable water loss management, and to develop analysis tools that provide more precise and accurate analysis. For this purpose, web-based, integrated "water balance", "minimum night flow" and "infrastructure leakage index" calculation tools have been developed and an application has been made for the pilot data set. It is thought that these calculation tools will provide significant contributions in the management of spills, monitoring water loss management performances, ensuring system efficiency, making leakage calculations more systematically and precisely, and making water loss management calculations in accordance with international standards.
\end{abstract}

Keywords: Analysis tool, Water balance, Water distribution system, Water losses, Water loss management

\footnotetext{
*a Mahmut FIRAT; mahmut.firat@inonu.edu.tr, Tel: (0422)377 48 80, orcid.org/0000-0002-8010-9289

${ }^{\mathrm{b}}$ orcid.org/0000-0002-3206-1225 c orcid.org/0000-0002-0987-1297
} 


\section{Giriş}

$\mathrm{Su}$ kayıplarının en önemli bileşeni olan fiziki kayılar, kaynaktan aboneye kadar olan tüm aşamalarda meydana gelebilmekte ve su kaynağının verimsiz kullanılmasına neden olmaktadır. Fiziki kayıpların önlenmesi ve yönetilmesi için, kayıp bileşenlerinin bilinmesi, doğru araç ve yöntemlerle analiz yapılması, sızıntı oluşma şekline göre (belirsiz, rapor edilen ve rapor edilmeyen) en uygun stratejinin belirlenmesi ve izleme politikasının ortaya konulması gerekir. Bunların uygulanmasıyla, su kaynağ 1 verimliliğinin sağlanması, daha az su üretilmesi, arıza bakım onarım maliyetlerinin düşürülmesi, abonelere yüksek hizmet kalitesinde güvenilir su iletilmesi mümkün olacaktır. Fiziki kayıpların izlenmesinde ve yönetilmesinde, standart su dengesinin uygulanmasi ve performansin izlenmesi (Mutikanga vd., 2009; Puust vd., 2010; Mutikanga vd., 2013; Songur vd., 2013; Zyoud vd., 2016; Eggimann vd., 2017; McKenzie vd., 2008; Gupta ve Kulat 2018), minimum gece debisinin izlenmesi, günlük olarak potansiyel önlenebilir sızıntıların belirlenmesi (Fallis vd., 2011; Eugine, 2017; Farah ve Shahrour, 2017; García ve Cabrera, 2007; Zaman vd., 2020), fiziki kayıplarla mücadelede sistemin performansının izlenmesi ve diğer sistemlerle kıyaslanması için altyapı kaçak indeksinin hesaplanması (Liemberger ve Farley, 2004; Farley ve Liemberger, 2005; Liemberger vd., 2007; Hamilton vd., 2006), basınç yönetiminin uygulanması (Fantozzi vd., 2009; Roshani ve Filion, 2014; Fontana vd., 2018) ve boru malzemesi yönetimi (Kleiner vd., 2001; Moglia vd., 2006; Nafi vd., 2008; Mann ve Frey, 2011; Cavazzini vd., 2020) gibi çeşitli yöntemler uygulanmaktadır. Bu yöntemlerin seçilmesinde ve uygulanmasında, sistemin mevcut koşulları, İdarenin bakış açısı, ekonomik ve alt yapı koşulları gibi birçok faktör etkilidir. García ve Cabrera (2007) minimum gece debisi yardımıyla günlük sızıntıları analiz etmiş, su kayıp hacimlerini etkileyen faktörleri analiz etmiş ve debi-basınç ilişkisini ifade eden denklemi kullanarak tahmin gerçekleştirmiştir. Cheung vd., (2010) su şebekelerindeki kayıpların değerlendirilmesinde İdareler tarafından sıklıkla kullanılan minimum gece debisi analizi yöntemi ile kalibrasyon sürecinde kaçakları tahmin etmek için yeni bir hesaplama metodolojisi geliştirmiştir. Sonuçlar, kalibrasyon metodu (49.73 m3) ve minimum gece debisi (MNF) metodu (52.53 m3) kaçak tahminlerinin benzer sonuçlar verdiğini, kalibrasyon yönteminin gerçeğe daha çok yakınsama yaptığını göstermiştir. Karadirek vd., (2012) su kayıplarının değerlendirilmesi ve analizi için 18 izole bölgede SCADA sistemi ile izleme gerçekleştirmiştir. Çalışmada, izole bölgelerde minimum gece debi analizi yapılmış, alt yapı kaçak indeksi hesaplanmış ve performans analiz edilmiştir. Toprak vd., (2013) dağıtım sistemlerindeki kayıpların izlenmesi ve önlenmesi gerektiğini vurgulamıştır. Çalışmada, dağıtım sistemlerindeki kayıpların belirlenmesi için fuzzy kural tabanlı model geliştirilmiş ve saha verileri kullanılarak test edilmiştir. Fuzzy kural tabanlı modelin su kayıpların belirlenmesinde güvenilir sonuçlar verdiği ifade edilmiştir. Choi vd., (2015) su kayıplarının değerlendirilmesinde kullanılan su dengesi ve sızıntı tahmini gibi yöntemlerin aksine yeterli verinin elde edilemediği sistemler için, olasılık yöntemine dayalı Bayesian yaklaşımının kullanılmasını önermiştir. Eugine (2017) içmesuyu dağıtım sistemlerindeki kayıpların hesaplanmasında ölçülebilir alt bölge, su dengesi yöntemi ve gece akışının modellenmesi gibi yöntemleri esas alarak yeni bir model geliştirmiş ve modelin su dağıtım sistemlerinde kaçak tahminlerinde iyi sonuç verdiğini ifade etmiştir. Farah ve Shahrour (2017) su kayıplarını tahmin etmek için geliştirilmiş minimum gece debisi yöntemiyle birlikte kullanılan akış eşiklerini belirleyerek yöntemi iyileştirmeyi amaçlamıştır. Geliştirilen strateji yüksek düzeyde sızıntı tespitine olanak sağlamakta ve 2015 yılında \%43 olan kayıp oranı 2016 yılında $\% 7$ değerine düşürülmüsstür. Karadirek (2017) su kayıplarının yönetilmesinin dağıtım sistemlerinin verimliliğinin iyileştirilmesinde, su ve enerji verimliliğinin sağlanmasında önemli katk1 sunduğunu vurgulamıştır. Çalışmada Türkiye'de kayıp oranının yaklaşı $\% 43.6$ seviyesinde olduğu ifade edilmiştir. Çalışmada su kayıplarının değerlendirilmesinde çeşitli performans göstergeleri dikkate alınmış ve uygulama gerçekleştirmiştir. Jadhao ve Gupta (2018) bir su şebekesinin hidrolik modelinin gerçek zamanlı akış ve basınç verilerini kullanarak kalibrasyonunu kurmayı hedeflemişlerdir. Bunun için, boru uzunlukları, çapları, montaj yılı ve malzemesi, sisteme verilen toplam su hacmi, tüketilen su hacmi, günlük su tüketimi, faturalandırılan su tüketimi, basınç, akış, vana tipi, sayısı ve cinsi, abone say1s1, nüfus gibi parametreler elde edilmiştir. Karakaya ve Toprak (2018) su kaynaklarının sınırlı olması, suya erişimin ve şebeke maliyetinin artması nedeniyle mevcut içme suyu şebekelerindeki kayıp ve kaçakların izlenmesinin ve kontrolünün önem kazandığını ifade etmiştir. Çalışmada, içme suyu dağıtım sistemlerindeki kayıp ve kaçakların önlenmesi için doğru bir şekilde tespitinin yapılması gerektiği vurgulanmış ve ZFT algoritması kullanılarak 
Türkiye'de içme suyu şebekelerindeki kayıp ve kaçaklar sınıflandırılmıştır. Lipiwattanakarn vd., (2019) sızıntıların önlenmesi ve azaltılmasının enerji ve sistem işletme maliyeti üzerindeki etkilerini araştırmıştır. Uygulama alanında izole bölgede sizıntıların onarılmasindan sonra izole bölge giriş debisinin \%9 azaldığını, buna bağlı olarak sistem giriş enerjisinde ise $\% 8$ azalma tespit edildiği, aktif kaçak kontrolü uygulanmasıyla sistem verimliliğinin iyileștiği vurgulanmıştır. Creaco vd., (2019) gerçek zamanlı kontrol ve otomasyon sistemleri ile su dağıtım sistemlerinin ve bileşenlerinin (sistem basınc1, depo seviye, pompa çalışma süresi ve enerji optimizasyonu, basınç kontrol vanaları vb.) izlenmesi ve kontrol edilmesinde önemli faydalar sağladığını vurgulamıştır. Boztaş vd., (2019) dağıtım sistemlerinde servis bağlantılarında meydana gelen arızaların sızıntılara ve su kayıplarına etkisini araştırmış ve saha verilerine göre servis bağlantılarında işçilik ve malzeme kalitesi iyileştirilerek arıza ve sızıntı oranının azaltılabileceğini vurgulamıştır. Yazdekhasti vd., (2020) su ve ekonomik verimliliğin sağlanması ve sürdürülebilir kentsel su yönetiminin sağlanması için sızıntıların tespit edilmesi ve bunun için en uygun tespit yöntem ve ekipmanlarının kullanılması gerektiğini ifade etmiştir. Jafari-Asl vd., (2020) dağıtım sistemlerinde basıncın sizıntı üzerindeki etkisinin azaltılması için optimizasyon tabanlı bir model ile basincin azaltılması ve yönetilmesini amaçlamış ve basıncın izlenmesi ile sızıntıların önemli oranda azaltılabileceği vurgulanmıştır.

$\mathrm{Bu}$ çalışmada, su kayıp yönetiminin sistematik, planlı ve sürdürülebilir bir şekilde yapılmasına esas teşkil eden temel su kayıp analizlerinin gerçekleştirilmesi ve daha hassas ve doğru analiz imkanı sunan hesaplama araçlarının geliştirilmesi amaçlanmıştır. Bunun için web tabanlı çalışan, birbiri ile bütünleşik olan "su dengesi", "minimum gece debisi (MNF)" ve "Altyapı Kaçak İndeksi (ILI)" hesaplama araçları geliştirilmiş ve pilot veri seti için uygulama gerçekleştirilmiştir. Geliştirilen bu araçların avantajları, kullanım şekilleri ve $\mathrm{Su}$ İdareleri ve Belediyeler için sağlayacağı faydalar, temel bileşenlerin su kayıp yönetimindeki rolü tartışılmıştır.

\section{Materyal ve metot}

\subsection{Su kayıp yönetimi ve önemi}

Dağıtım sistemlerinde veya iletim hatlarında, fiziksel, çevresel ve işletme faktörlerine bağlı olarak oluşan sızıntıların farkına varılması, tespit edilmesi, önlenmesi, kontrolü ve yönetilmesi oldukça maliyetli ve zaman alıcı süreç ve yöntemleri içermektedir (Liemberger ve Farley 2004; Farley vd., 2008). Su İdarelerinde su kayıp yönetimi kapsamında bahsedilen bu faaliyetlerin yapılabilmesi için teknik, teknolojik, ekonomik, personel ve ekipman anlamında yeterli alt yapının olması ve en önemlisi uzun dönemli stratejik planın yapılması gerekmektedir (Farley ve Liemberger 2005). Su kayıpları, idari ve fiziki kayılar olmak üzere iki farklı türde kayıp meydana gelmekte ve bunların oluşmasında oldukça fazla faktör etkili olmaktadır (Lambert, 2002; Farley vd., 2008). İdari kayıplar, aboneler tarafından tüketilen ancak ücreti alınmayan bileşenleri içermektedir. Fiziki kayıplar ise, isale hattı, dağıtım sistemi ve elemanlarında meydana gelen sızıntıları kapsamaktadır. $\mathrm{Bu}$ kayıpların hacimsel olarak en yüksek oranını oluşturan fiziki kayıplar, oluşma şekline göre; belirsiz (arkaplan) sızıntılar, rapor edilen ve rapor edilmeyen sızıntılar şeklinde sınıflandırılmaktadır (Lambert, 2002; Lambert ve Liemberger, 2007; Farley vd., 2008). Belirsiz sızıntılarda, sızıntı debisi genellikle 250 litre/saat değerinden küçük olmakta, bağlantı noktaları veya boru gövdesinde küçük kılcal çatlaklarda gözlenmekte ve akustik yöntemlerle tespit edilmesi mümkün olmamaktadır (Lambert, 2002; Farley vd., 2008). Diğer taraftan, arızaların belli bir kısmı yüksek basınç ve arızanın meydana geldiği yer gibi birçok faktöre bağlı olarak yüzeye çıkmakta, farkına varılması ve yerinin tespiti daha kısa sürede gerçekleşmekte ve onarılmaktadır. Ancak fiziki kayıpların önemli bir kısmı yüzeye çıkmamakta (rapor edilmeyen sizıntılar) ve farkına varılmas1, belirlenmesi ve önlenmesi için aktif kaçak kontrolü (ALC) yönteminin uygulanması gerekmektedir (McKenzie vd., 2002; Farley ve Liemberger 2005; Mutikanga vd., 2013). ALC, temel olarak yüzeye çıkmayan arızaların belirlenmesi, yerinin tespit edilmesi ve onarılması faaliyetlerimi kapsamaktadır. ALC, birçok yöntem ve aracı içerdiği için sistemin koşulları, mevcut işletme özellikleri, uygulanacak yöntemlerin gereksinimleri gibi faktörler göz önüne alınmalıdır. Ayrıca bu yöntemlere ait hesaplamaların yapılması, sonuçların değerlendirilmesi ve performansının izlenmesi için sistematik yaklaşımların veya hesaplama araçlarının uygulanması önemli katkılar sunmaktadır. Ancak birçok İdarede su kayıp yönetiminde genelde rapor edilen sızıntıların onarılmasını ve mücadelesini esas alan pasif kaçak kontrolü yeterli görülmekte ve ALC yöntemleri dikkate alınmamaktadır. ALC yaklaşımının uygulanmamasının sebepleri temel olarak, (i) İdarenin su kaynağı sorununun olmaması veya su üretimi için enerji maliyetlerinin 
çok düşük olması, (ii) yönetimin gerekli önemi vermemesi, farkındalığın olmaması, (iii) İdarede ALC uygulanması için gerekli alt yapı koşullarının olmaması, şeklinde açıklanabilir. Ancak sürdürülebilir kentsel su yönetiminde, (i) su ve enerji verimliliğinin sağlanması, (ii) yeni kaynak kullanımın ötelenmesi, (iii) su üretim ve işletme maliyetlerinin azaltılması, (iv) hizmet kalitesinin iyileştirilmesi, abone memnuniyetinin ve uzun dönemli su kayıp yönetiminin sağlanması için, doğru ve uygun yöntemleri ve araçları içeren ALC yaklaşımının uygulanması oldukça önemlidir.

\subsection{Temel su kayıp analizleri için hesaplama araçlarının geliştirilmesi}

$\mathrm{Su}$ kayıp yönetiminde ALC yaklaşımı altında uygulanan temel yöntemler, (i) Uluslararası $\mathrm{Su}$ Birliği (IWA) standart su dengesi metodolojisi, (ii) minimum gece debisi analizi, (iii) alt yapı kaçak indeksi (ILI) ile sızıntı analizi, şeklinde verilebilir. $\mathrm{Bu}$ yöntemlerin sadece bir veya birkaçının uygulanması sistemde iyileştirme sağlasa da, tam anlamiyla sistemi temsil edecek analizin ortaya konulması ve sürdürülebilir bir şekilde uygulanması açısından tamamının uygulanması gerekir. Ancak bu yöntemlerin uygulanmas1, sonuçların çapraz doğrulanması ve en önemlisi bu analizlerin sistematik ve doğru bir şekilde yapılması için kullanıcı dostu hesaplama araçlarının kullanılması gerekir. Bu çalışmada su kayıp analizlerini gerçekleştiren, Su İdareleri ve Belediyeler için daha hassas ve kolay analiz imkânı sunan ve en önemlisi birbiri ile bütünleşik çalışan modüllerden oluşan "temel su kayıp analizleri için hesaplama araçları" geliştirilmiştir. Geliştirilen bu araçlar toplamda üç modülden oluşmakta, veri ve analiz sonuçları birbiri ile bütünleşik çalışmakta ve literatürde önerilen sınır değerler ile İdarenin performansını kıyaslama imkânı sunmaktadır. Ülkemizde son yıllarda sürdürülebilir su kayıp yönetimi için ALC ve bileşenleri (izole bölgelerin oluşturulması) uygulanmaktadır. Özellikle izole ölçüm bölgelerinin oluşturulması diğer yöntemler için temel teşkil etme özelliğindedir. Su kayıplarının azaltılması amaciyla 2016-2018 yılları arasinda Malatya Su ve Kanal İdaresi tarafindan merkez dağıtım sisteminde izole bölge çalışmaları gerçekleştirilmiştir. $\mathrm{Bu}$ çalışmada su kayıp yönetimi için temel bileşenlerin hesaplanması ve bu hesaplamaların gerçekleştirilmesi için geliştirilen hesaplama araçlarının test edilmesi amacıyla Malatya içme suyu dağıtım sisteminde oluşturulan ve karakteristik özellikleri Tablo 1'de verilen 5 pilot bölgeye ait veri setleri kullanılmıştır (MASKİ, 2018).

\section{Bulgular}

\subsection{Standart su dengesi analiz modülü}

$\mathrm{Su}$ kayıpları ve alt bileşenlerinin hesaplanması, değişimlerin izlenmesi ve performansının analizinde kullanılan en temel araç IWA tarafından önerilen standart su dengesi yöntemidir (Lambert vd., 1999; Lambert, 2002). Literatürde su kayıplarının değerlendirilmesi ve su dengesinin hesaplanmasinda, AWWA (2014) tarafindan önerilen (excel tabanl1) "AWWA water audit software" ve Liemberger vd. (2018) tarafindan "WB-EasyCalc software" önerilmiştir. Su dengesinin saha verilerine göre doldurulması durumunda, su kayıplarının alt bileşenleri hakkında değerlendirme yapılması, iyileştirilmesi gereken alanların belirlenmesi ve öncelik verilmesi gereken bileşenlerin belirlenmesi mümkün olmaktadır. Ancak özellikle yeterli alt yapının olmadığı İdarelerde bileşenlere ait verilerin temin edilmesi birçok durumda mümkün olmayıp sadece tahmini bir şekilde doldurulmaktadır. Tablonun bu şekilde doldurulması, İdare için referans oluşturacak verilerin üretilmesine ve performansin iyileştirilmesi için öncelikli müdahale edilecek bileşenlerin belirlenmesine engel olmaktadır. Daha hassas analiz ve değerlendirme yapabilmek ve sahayı temsil edecek veri üretebilmek için bu yöntemlerin birlikte kullanılması ve doğrulama yapılması oldukça önemlidir. $\mathrm{Su}$ tüketim karakteristiği, şebeke ve abone davranışı, sistem giriş debisi ve arıza oranları mevsimsel olarak değiştiğinden dolayı, su kayıp yönetiminde su dengesi ile analiz yapilırken genelde yıllık olarak bütçe çıkarılması ve buna göre değerlendirme yapılması gerekir. Ancak izole bölge veya sistemin performansının izlenmesi ve analiz edilmesi açısından aylık olarak da doldurulur. Ülkemizde Su İdarelerinde yıllık su bütçesinin yapılması ve performansının izlenmesi için su dengesinin doldurulması ve yıllık olarak Bakanlığa bildirilmesi istenmektedir. $\mathrm{Su}$ dengesinin sistematik ve doğru bir şekilde doldurulması için ve kullanıcıların daha kolay analiz yapması için uygun hesaplama araçlarının kullanılması önemlidir. Bu nedenle bu çalışmada Su İdarelerinin daha kolay ve hassas analiz yapmasına imkan tanıyan ve bölge veya sistem performansını izleme imkanı sunan web tabanlı "su dengesi hesaplama aracı” geliştirilmiştir (Şekil 1). Geliştirilen hesaplama arac1, T.C Tarım ve Orman Bakanlığı'nın İdarelerinden ve Belediyelerden talep ettiği hesaplamaları içermektedir. Veri giriş ekranı incelendiğinde, bir sistem için giriş debisinin yanı sıra eğer sistemden çıkış varsa bu değerin de girilmesi istenmekte ve buna göre 
"Sistem net giriş (SIV)" hesaplanmaktadır. Ayrıca, bileşenlere ait değerlerin hacim veya SIV \% si şeklinde giriş veri girişi yapılabilmektedir. Su dengesi analizinde yapılan en önemli hata sayaçlarda meydana gelen kayıpların hesaplanmasında gösterilebilir.

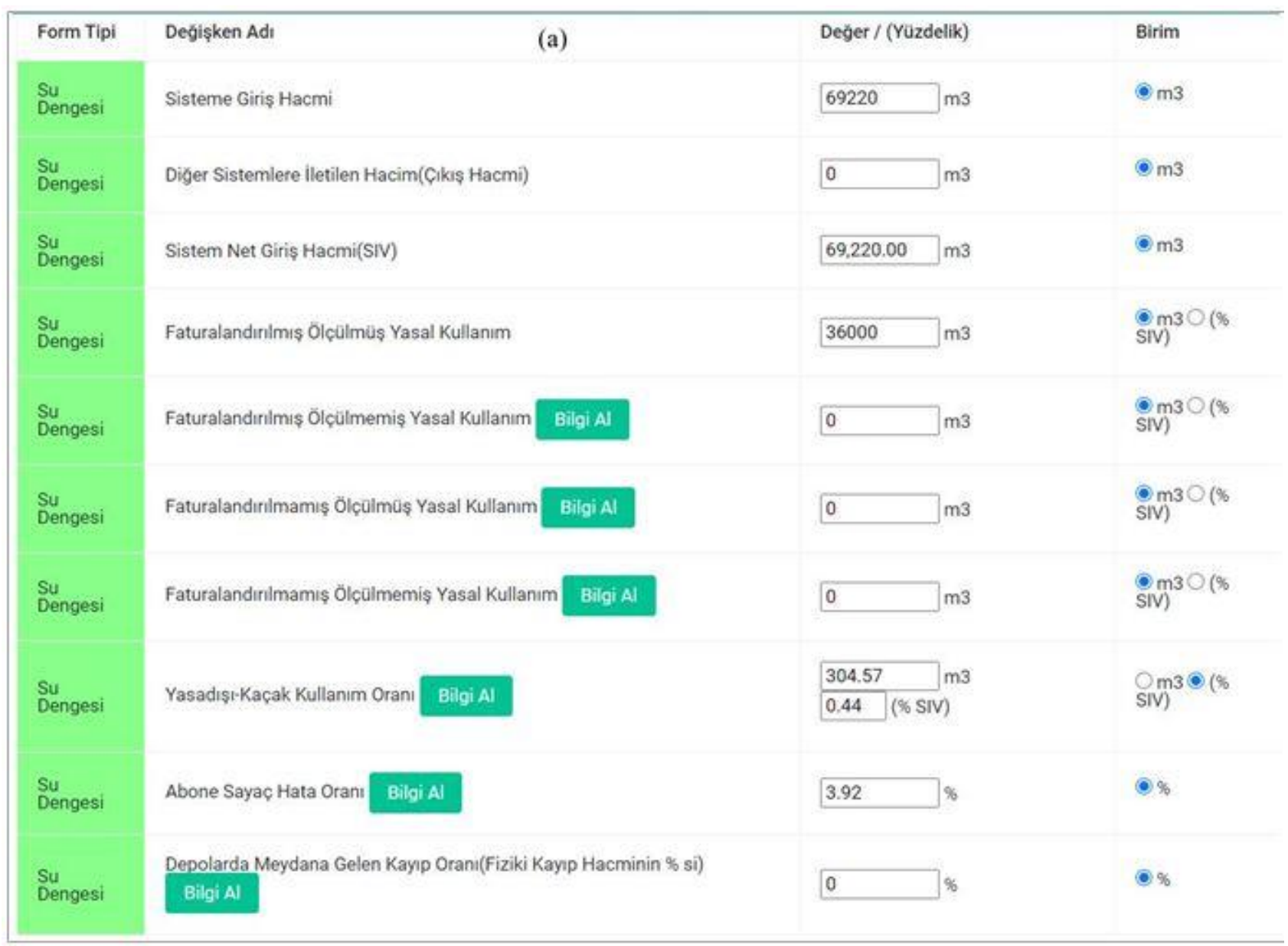

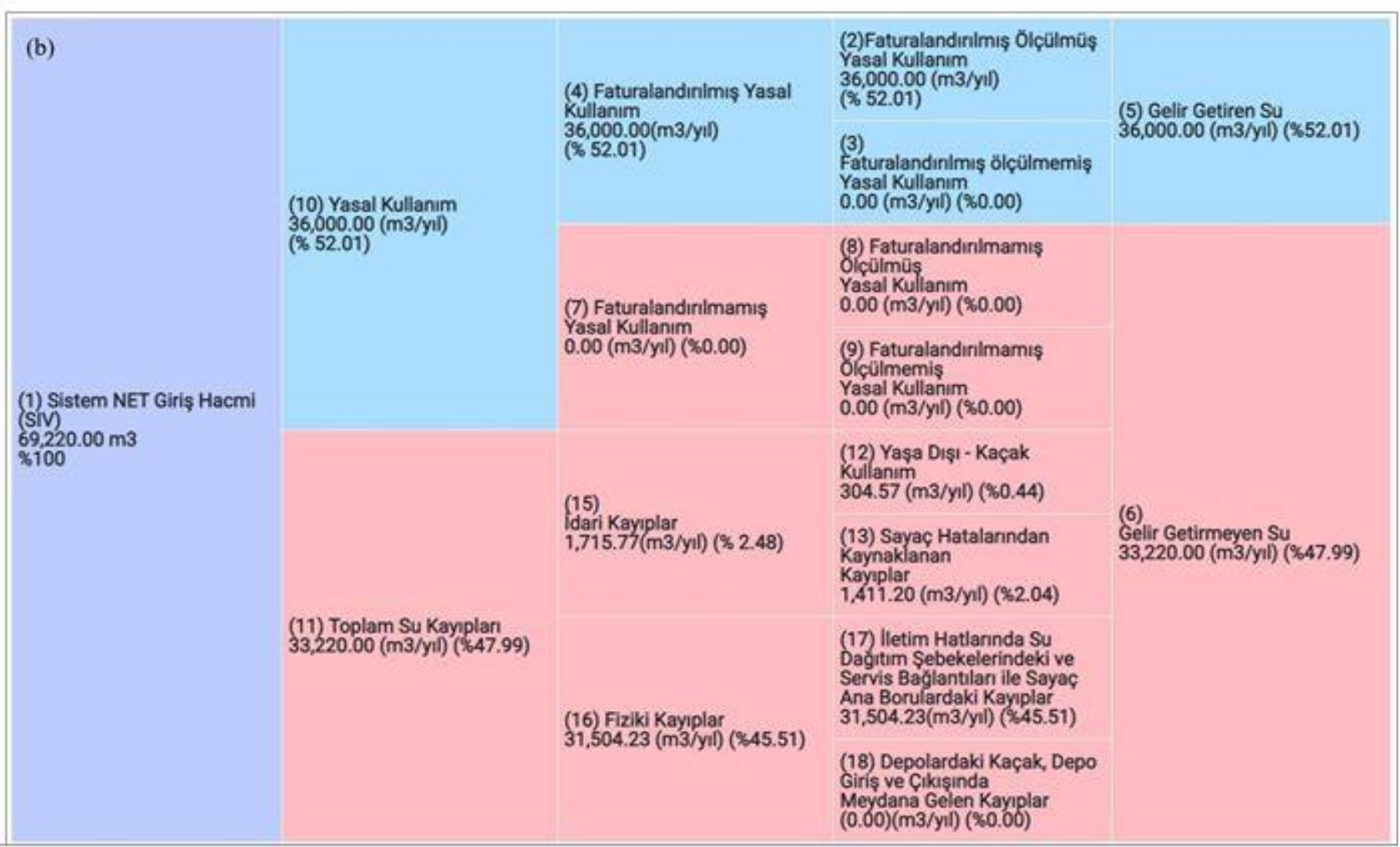

Şekil 1. Web tabanlı su dengesi hesaplama aracı ve pilot bölge için analiz sonuçları a) Veri giriş ekranı b) Sonuç ekranı 
Şekil 1'deki su dengesi tablosunda, faturalandırılmış ölçülmüş tüketim, yasal abone tüketimlerini içermektedir. Faturalandırılmamış ölçülmüş kullanımlar, cami, park-peyzaj gibi yasal ancak ücreti alınmayan tüketimlerdir. Ayrıca faturalandırılmamış ölçülmemiş kullanımlar, yangın hidrantı, itfaiye gibi yasal, ölçülemeyen ve ücreti alınmayan tüketimleri kapsamaktadır. Sayaç hatalarından kaynaklanan kayıplar, yasal abone sayaçlarındaki ölçüm hatalarının neden olduğu kayılardır. $\mathrm{Bu}$ bileşende yasal abone tüketimi olduğu halde ücret alınmamaktadır. Gelir getirmeyen su, sisteme verilen ancak ücreti alınamayan bileşenleri içermektedir. Gelir getiren $\mathrm{su}$ ise, sistemde ücreti alınan yasal faturalandırılmış tüketimleri içerir.

\subsection{Minimum gece debisi analiz modülü}

Minimum gece debisi (MNF), rapor edilmeyen sızıntıların farkına varılmasında günlük olarak uygulanan en temel yaklaşımdır (Lambert vd., 1999; Liemberger ve Farley, 2004; Wu vd., 2018). $\mathrm{Bu}$ yöntemde temel prensip, su talebinin en düşük olduğu gece 02:00-04:00 saatleri arasinda sistem giriş debisinin izlenmesi, gece yasal tüketimlerin tahmin edilmesi ve sistemdeki belirsiz sızıntıların hesaplanması, giriş debisinden bu iki bileşenin çıkarılması ile "akustik yöntemlerle tespit edilen potansiyel önlenebilir sızıntının" belirlenmesi şeklindedir (Lambert vd., 1999; Liemberger ve Farley 2004). Bunları gerçekleştirebilmek için, izole bir bölgenin tanımlanmış olması, bölge girişinde debi ve basıncın sürekli izlenmesi, insani gece tüketiminin ve belirsiz sızıntıların Burst and Background Estimate (BABE) denklemine göre tahmin edilmesi (Lambert, 1994) gerekir. Lambert (1994) tarafindan önerilen ve MNF analizinde bu iki bileşenin tahmin edilmesi için geliştirilen BABE denklemi en temel yöntemdir. Gece tüketim hesabında (i) abone türü ve sayısı (konut, ticari), (ii) yaşayan kişi sayısı gibi veriler kullanılmaktadır. Belirsiz sızıntı hesabında ise, (i) şebeke uzunluğu $(\mathrm{km})$, (ii) servis bağlantı sayısı (ana hat parsel aras1), (iii) özel mülkteki servis bağlantı uzunluğu (km) (parsel bina arası), (iv) işletme basıncı, (vi) sistem fiziksel durumuna ihtiyaç duyulmaktadır (Lambert, 1994; Lambert vd., 1999; Lambert 2002). Bu analizlerin sistematik yapılması, verilerin doğru girilmesi, katsayıların doğru belirlenmesi ve sistem karakteristiğine uygun bileşenlerin seçilmesi önemlidir. $\mathrm{Bu}$ nedenle bu çalışmada, MNF analizinin gerçekleştirilmesi, gece yasal tüketimlerin ve belirsiz sizıntıların doğru bir şekilde hesaplanması, katsayıların doğru bir şekilde seçilmesi ve en önemlisi kullanıcıların için hassas ve doğru analiz gerçekleştirilmesi için "minimum gece debisi hesaplama arac1" geliştirilmiştir (Şekil 2). Bu hesaplama aracının belirsiz sızıntı hesabında sağladığı avantajlar şu şekilde verilebilir;

- Şebeke veya servis bağlantılarının fiziki durumuna göre sızıntı katsayılarını belirleyen ICF katsayısının ve birim sizıntı katsayısının (C1) seçilebilir olması (Şekil 4 a),

- Servis bağlantılarında sayacın yerleşim durumuna (parsel sinırında veya binada) ve fiziksel durumuna göre C2 katsayısının seçilebilir olması (Şekil 4 b),

- Veri toplama durumun dikkate alınması, "tahmini veri" veya "gerçek saha verisi" seçeneklerini sunulması, buna göre hesaplama katsayılarının dikkate alınması (Şekil 3),

- Basınç düzeltme katsayısının farklı yöntemlere göre yapılabilmesi (Şekil 4c)

Ayrıca, gece yasal tüketim hesabında sağladığı kolaylıklar; (i) tüketim hesabında verisi bilinen bileşenlerin (abone sayısının ve türünün veya nüfusun) seçilebilir olması (Şekil 4 d), (ii) literatürde önerilen tüketim katsayılarının kullanılması veya bölgeye özel katsayılarının kullanılabilir olması şeklindedir. Bu hesaplamalar sonucunda giriş debisi dikkate alınarak "potansiyel olarak önlenebilir sizıntı" belirlenmektedir. $\mathrm{Bu}$ hesaplamalar günlük olarak yapılmakta, kullanıcılar için bölgeye ait önlenebilir sızıntılar belirlenmekte ve basınç seviyelerine göre sızıntı miktarı analiz edilmektedir. Bu hesaplama aracının İdarelerde, sizıntıların yönetilmesinde, sistem verimliliğinin sağlanmasında ve sızıntı hesaplarının daha sistematik ve hassas bir şekilde yapılmasında önemli katkılar sunacağı düşünülmektedir. Tablo 1'de verilen sonuçlara göre, MNF ölçüm değeri, sistem girişinde gece saatlerinde ölçülen debiyi temsil etmektedir. Bölgenin özelliklerine göre bu debinin düşük seviyede tutulması esastır. Diğer taraftan hesaplama aracı kullanılarak MNF hesap değerleri elde edildikten sonra aradaki fark bölgede akustik yöntemlerle tespit edilmesi gereken sizıntıları göstermektedir. Görüldüğü gibi MNF değerinin hesaplanması, İdareler için önleme stratejilerinin geliştirilmesi ve yöntemlerin aktif şekilde uygulanması noktası referans oluşturma potansiyeli bulunmaktadır. 


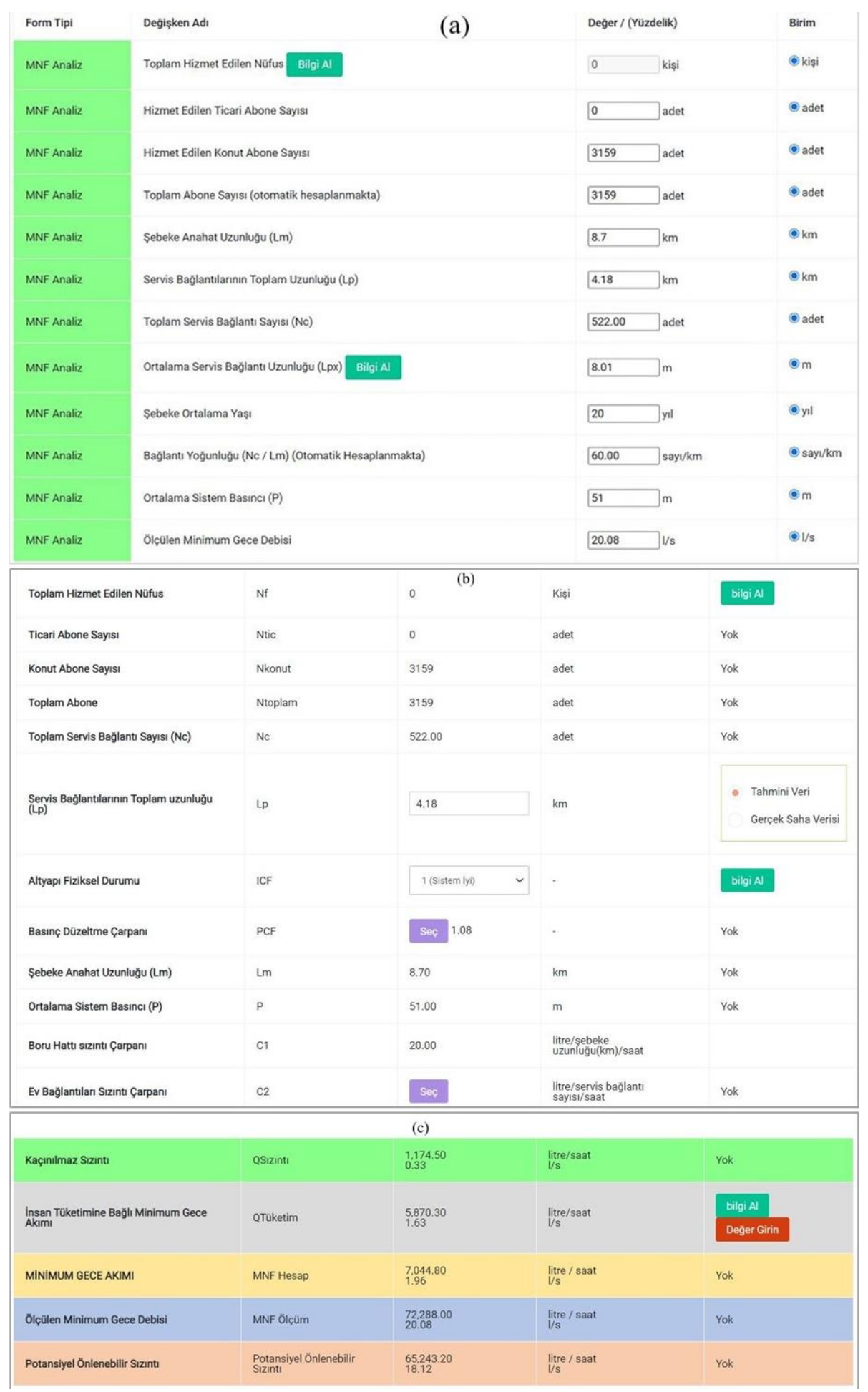

Şekil 2. Minimum gece debisi hesaplama aracı a) Veri giriş ekranı b) Katsayı belirleme ekranı c) Sonuç ekranı 


\begin{tabular}{|c|c|c|c|c|c|c|c|}
\hline \multicolumn{8}{|c|}{ (a) } \\
\hline Katsayı & \multicolumn{7}{|c|}{ Şebeke Fiziksel Durumuna Göre Katsayıların Belirlenmesi } \\
\hline Altyapı Fiziksel Durumu (ICF) & $\begin{array}{c}1 \\
\text { (Sistem Iyi) }\end{array}$ & 1.5 & $\begin{array}{l}2 \\
\text { (Sistem } \\
\text { orta) }\end{array}$ & 2.5 & $\begin{array}{c}3 \\
\text { (Sistem } \\
\text { Kötü) } \\
\end{array}$ & 3.5 & $\begin{array}{c}4 \\
\text { (Sistem } \\
\text { Çok Kötü) }\end{array}$ \\
\hline $\mathrm{C}_{1} \quad($ litre $/ \mathrm{km} / \mathrm{saat})$ & 20.00 & 30.00 & 40.00 & 50.00 & 60.00 & 70.00 & 80.00 \\
\hline $\begin{array}{c}\mathrm{C}_{2} \text { (abone sayac1/kontrol sayacı } \\
\text { parsel smurunda ise) (litre/servis } \\
\text { bağlantı/saat) }\end{array}$ & 1.25 & 1.88 & 2.50 & 3.13 & 3.75 & 4.38 & 5.00 \\
\hline $\begin{array}{c}\text { C2a (abone sayacı/kontrol sayacı } \\
\text { binada ise) (litre/servis bağlantı } \\
\text { uzunluğ (m)/ saat) }\end{array}$ & 1.750 & 2.625 & 3.500 & 4.375 & 5.250 & 6.125 & 7.000 \\
\hline $\begin{array}{c}\mathrm{C} 2 \mathrm{~b} \text { (abone sayac1/kontrol sayacı } \\
\text { binada ise) (litre/servis bağlantı } \\
\text { uzunluğu }(\mathrm{km}) / \text { saat) }\end{array}$ & $(0.5 * 1000 * \mathrm{Lpx} / 15)$ & & & & & & \\
\hline
\end{tabular}

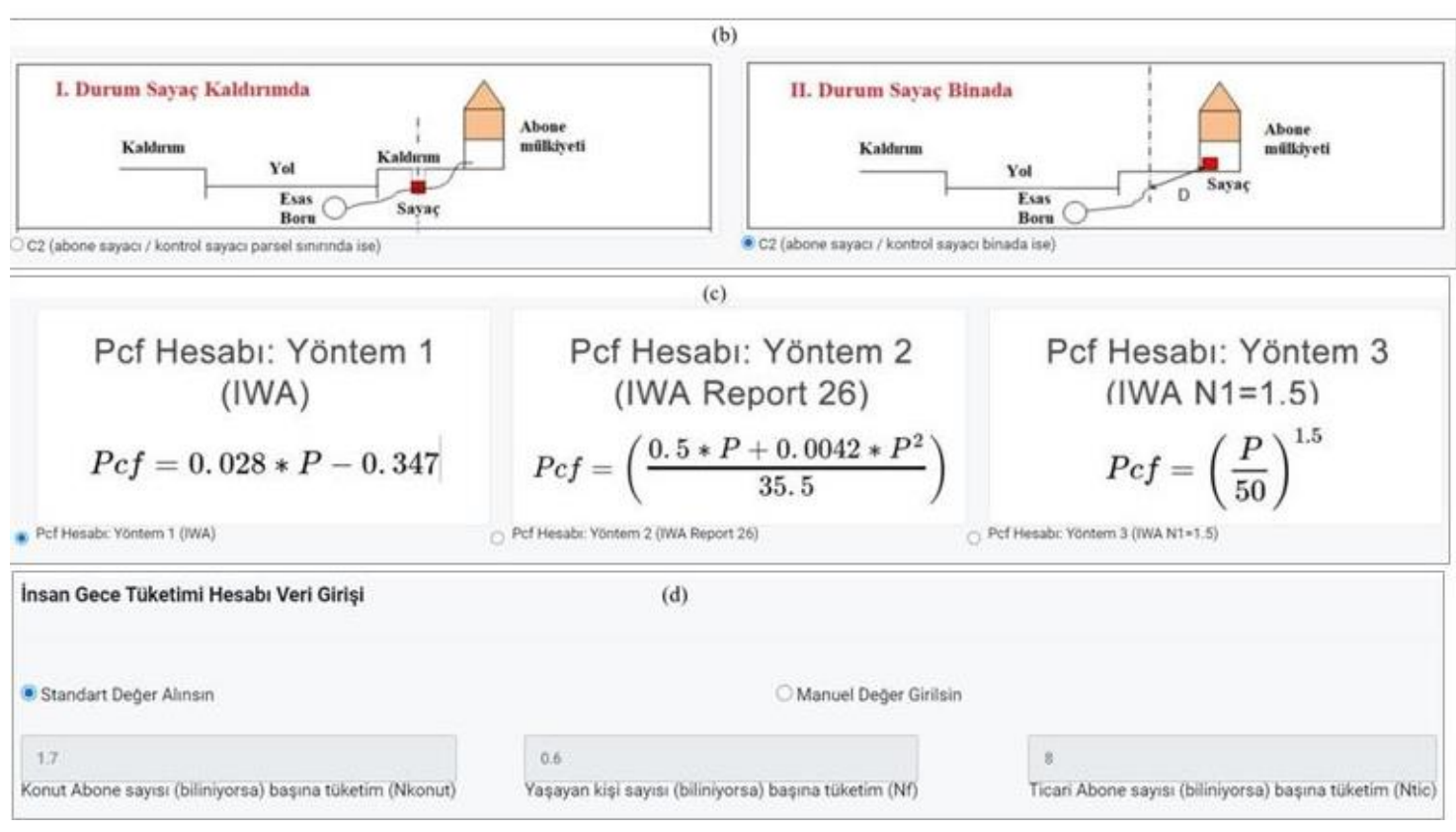

Şekil 3. MNF hesaplama aracında katsayıların seçilmesi a) ICF, C1 ve C2 katsayılarının seçilmesi b) Sayaç yerleşiminin seçimi c) Basınç düzeltme katsayısı için yöntem seçimi d) İnsan gece tüketimi için katsayı belirleme (Lambert, 2002; Farley, 2001; Morrison vd., 2007; Babić vd., 2014; Lambert vd., 2014)

\subsection{Altyapı kaçak indeksi (ılı) hesaplama aracı}

Performans kiyaslamada en önemli husus, kıyaslanabilir ve doğru göstergenin belirlenmesidir. Özellikle İdarelerin veya bölgelerin birbiri ile kıyaslanmasında doğru göstergenin seçilmesi gerekmektedir. Bu amaçla kullanılan en temel gösterge Lambert (1994) tarafindan önerilen "alt yapı kaçak indeksi (ILI)" gösterilebilir. Bu gösterge bir dağıtım sisteminde veya izole bölgede y1llık fiziki kayıp hacminin (CARL), yıllık kaçınılmayan fiziki kayıp (UARL) hacmine oranı şeklinde denklem (1) ile hesaplanmaktadır (Lambert, 1994; Lambert vd., 1999). Bu göstergenin hesaplanmasinda temel zorluklar şu şekilde verilebilir; (i) CARL değerinin su dengesine göre hesaplanmasında yaşanan sorunlar (tahmini verilerin kullanılması), (ii) UARL hesabında, şebeke bilgileri ve işletme basınc1 hakkında yeterli bilginin olmaması. ILI göstergesinin doğru hesaplanması ve en önemlisi çıkan sonucun doğru bir şekilde yorumlanması oldukça önemlidir. $\mathrm{Bu}$ gösterge özellikle sızıntıların yönetilmesinde uygulanacak yöntemlerin belirlenmesi açısından referans oluşturacak bilgiler sunmaktadır. UARL, bir dağıtım sisteminde teknik olarak sızıntının en düşük seviyesini göstermek olup Lambert vd. (1999) tarafından önerilen denklem (2) kullanılmaktadır.

$$
\begin{aligned}
& I L I=C A R L / U A R L \\
& U A R L=\left(18 * L_{m}+0.8 * N_{c}+25 * L_{p}\right) * P
\end{aligned}
$$


P; bölge ortalama basıncı (m), Lm; şebeke uzunluğu $(\mathrm{km}), \mathrm{Nc}$; servis bağlantı sayıs1 ve Lp; özel mülkteki boru uzunluğudur $(\mathrm{km})$. Bölgede su tüketim karakteristiğine bağlı olarak basınçtaki değişimleri dikkate alınması gerekir. Bu nedenle UARL hesabında bölgede ortalama basıncın elde edileceği noktada günlük düzenli basınç ölçümü yapılması ve buna göre ortalama basinın hesaplanması gerekir. Bu çalışmada, ILI ve UARL parametrelerinin sistematik bir şekilde hesaplanması, çıkan sonuçların yorumlanması, literatürde önerilen sınır değerlerle kıyaslanması ve böylelikle sistemin performansinın değerlendirilmesi için "altyap1 kaçak indeksi hesaplama aracı” geliştirilmiştir (Şekil 4). Bu hesaplama arac1, su dengesi ve minimum gece debisi hesaplama araçları ile bütünleşik çalışmakta, analiz için gerekli veriler otomatik çekilmektedir.

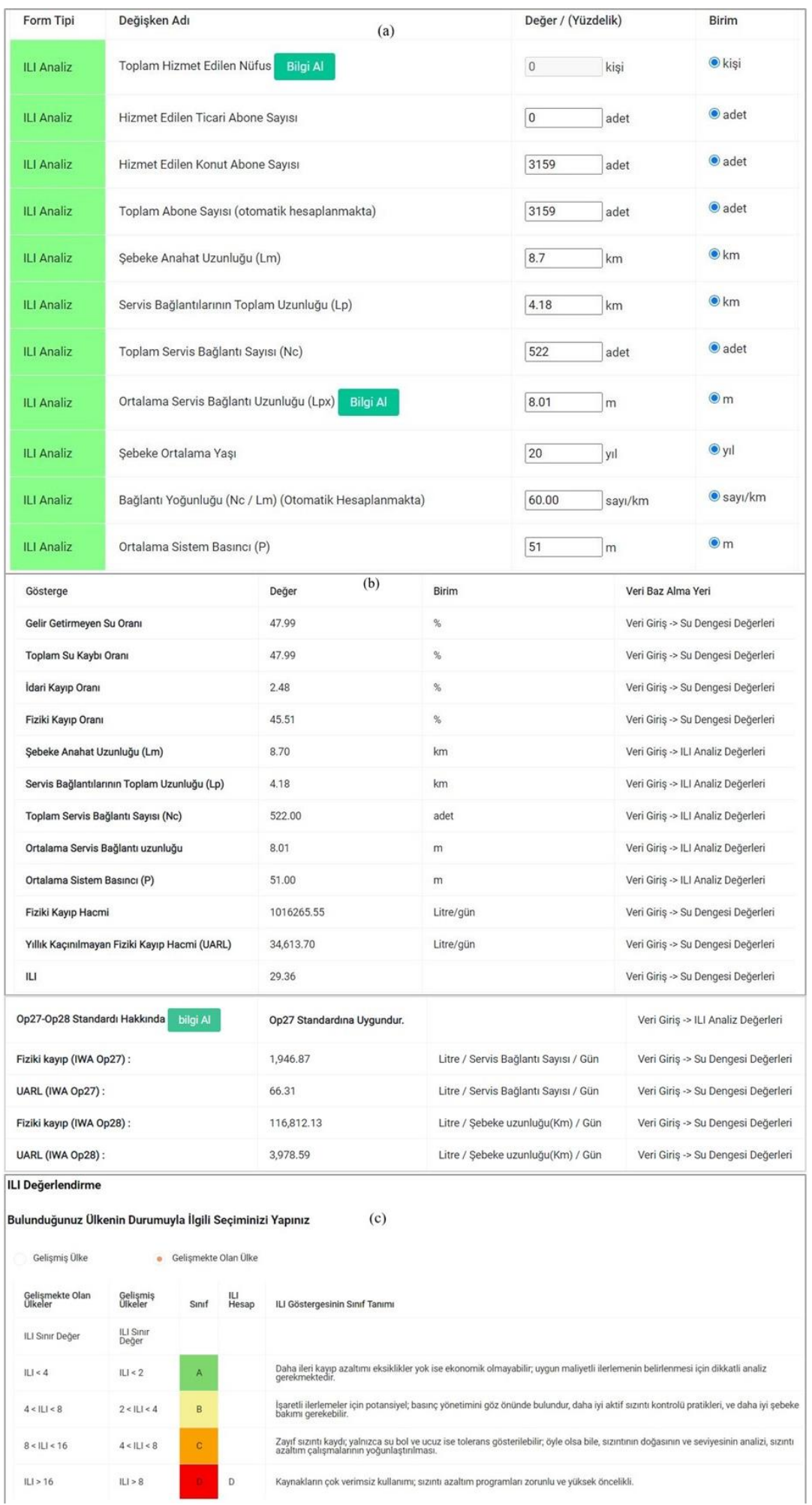

Şekil 4. Altyapı kaçak indeksi hesaplama aracı a) Veri giriş ekranı b) Analiz ekranı c) Sonuç değerlendirme ekranı 
Çalışma kapsamında 5 pilot veri seti için analiz yapılmış ve sonuçlar test edilmiştir (Tablo 1). Tabloda, MNF hesap, hesaplama yoluyla belirlenen gece yasal tüketimleri ve belirsiz sızıntıları içermektedir. MNF ölçüm, izole bölgelerde MNF saatinde giriş debimetresinde ölçülen debiyi temsil etmektedir. MNF ölçüm ve
MNF hesap parametrelerinin fark1, bölgede potansiyel olarak önlenebilir sızıntı değerini vermektedir. Gelir Getirmeyen Su (GGS) oran1, izole bölgede, sistem giriş hacmi ile yasal tüketimlerin fark1 olan gelir getirmeyen su hacminin sistem giriş hacmine şeklinde ifade edilmektedir.

Tablo 1. Pilot izole bölgeler için karakteristik bilgiler

\begin{tabular}{lllllllllll}
\hline Bölge & $\begin{array}{l}\mathbf{L m} \\
(\mathbf{k m})\end{array}$ & $\mathbf{N c}$ & $\begin{array}{l}\mathbf{L p} \\
(\mathbf{k m})\end{array}$ & $\begin{array}{l}\mathbf{( P )} \\
(\mathbf{m})\end{array}$ & $\mathbf{N a}$ & $\begin{array}{l}\text { MNF Ölçüm } \\
(\mathbf{l} / \mathbf{s})\end{array}$ & $\begin{array}{l}\text { MNF Hesap } \\
(\mathbf{l} / \mathbf{s})\end{array}$ & $\begin{array}{l}\text { Sızıntı } \\
(\mathbf{l} / \mathbf{s})\end{array}$ & $\begin{array}{l}\text { GGS } \\
(\boldsymbol{\%})\end{array}$ & $\begin{array}{l}\text { ILI } \\
---\end{array}$ \\
\hline DMA1 & 8.7 & 522 & 4.18 & 51 & 3159 & 20.08 & 2.9 & 17.14 & 48.0 & 29.3 \\
DMA2 & 5.65 & 500 & 4.08 & 38 & 3207 & 20.80 & 2.3 & 18.50 & 47.5 & 41.2 \\
DMA3 & 4.78 & 1046 & 2.52 & 45 & 1184 & 6.41 & 1.7 & 4.74 & 52.7 & 9.07 \\
DMA4 & 3.68 & 384 & 3.07 & 45 & 2167 & 6.31 & 1.73 & 4.58 & 26.9 & 11.5 \\
DMA5 & 7.43 & 537 & 4.3 & 50 & 779 & 9.9 & 1.46 & 8.44 & 73.6 & 29.7 \\
\hline
\end{tabular}

Burada, Nc: servis bağlantı sayısı, Lm: şebeke ana hat uzunluğu $(\mathrm{km}), \mathrm{Lp}$ : servis bağlantı uzunluğu $(\mathrm{km})$, P: bölge ortalama basincı (m), Na: abone sayısı şeklinde ifade edilir. Bu hesaplama aracında kullanıcı bölgedeki sayaç hata oranını girdikten sonra, IWA tarafindan tanımlanan standartta sayaçlardaki kayı hacmini otomatik hesaplanmaktadır. $\mathrm{Bu}$ hesaplama aracının, İdarelerde su kayı analizi ve bütçesinin oluşturulmasında önemli katkılar sunacağ 1 , daha hassas analiz imkanı sunacağı ve en önemlisi doğru ve güvenilir hesaplama sağlayacağı düşünülmektedir. Tabloda verilen sonuçlar değerlendirildiğinde, GGS oranları özellikle eski şebeke koşullarının olduğu bölgeler için oldukça yüksek seviyede olduğu görülmektedir. Diğer taraftan nispeten daha iyi şebekeye sahip olan Bölge-4 için bu oranının kabul edilebilir sınırlar içinde kaldığı söylenebilir. Bilindiği üzere Bakanlık tarafından yayınlanan yönetmekte kayıp oranının $\% 25$ seviyesine indirilmesi gerekmektedir. Uluslararas1 literatürde GGS oranlarının $\% 10$ civarında olması, şebekenin oldukça iyi durumda olduğu şeklinde değerlendirilmektedir. Su dengesinin hesaplanması, İdareler ve Belediyeler için önleme stratejilerinin geliştirilmesi için referans oluşturma potansiyeli bulunmaktadır. Tablo 1'de verilen sonuçlara göre, ILI değerinin küçük olması sistemin iyi seviyede olduğunu göstermektedir. Şekil 3'te verilen değerlendirme tablosuna göre sistemin yer aldığ sınıf belirlenmekte ve buna göre iyileştirme yöntemleri uygulanmaktadır. ILI değerinin hesaplanması, İdareler için önleme stratejilerinin geliştirilmesi ve yöntemlerin aktif şekilde uygulanması noktası referans oluşturma potansiyeli bulunmaktadır. Bu hesaplama aracının sağladığ1 avantajlar (Lambert vd., 1999; Lambert 2002; Liemberger vd., 2007); (i) herhangi bir işletme basıncı için UARL hesabının yapılması, (ii) ILI göstergesinin hassas bir şekilde hesaplanması, UARL ile kıyaslanmas1, (iii) UARL ve ILI değerlerinin literatürde önerilen gösterge kodlarına göre hesaplanması ve kıyaslanması, (iv) ILI gösterge sonucunun IWA tarafindan önerilen değerlendirme tablosuna göre klyaslanması ve İdare için referans oluşturacak bilginin üretilmesi şeklinde verilebilir. Sonuç olarak, bu hesaplama araçlarının, İdarelerde, sızıntıların yönetilmesinde, su kayıp yönetim performanslarının izlenmesinde, sistem verimliliğinin sağlanmasında, sızıntı hesaplarının daha sistematik ve hassas bir şekilde yapılmasında, su kayıp yönetimi hesaplamalarının uluslararası standartlara göre yapılmasında önemli katkılar sunacağı düşünülmektedir. ILI göstergesi sızıntı yönetiminde kullanılan en temel gösterge olarak ifade edilmektedir.

\section{Tartışma ve sonuçlar}

$\mathrm{Bu}$ çalışmada, su kayıp yönetiminin sistematik, planlı ve sürdürülebilir bir şekilde yapılmasına esas teşkil eden temel su kayıp analizleri için hassas ve doğru analiz imkanı sunan hesaplama araçları geliştirilmiş ve 5 farklı pilot veri setleri için test edilmiştir. Bunun için web tabanlı çalışan, birbiri ile bütünleşik olan "su dengesi", "minimum gece debisi" ve "ILI" hesaplama araçları geliştirilmiş ve pilot veri seti için uygulama gerçekleştirilmiştir. Bunun için, Su İdarelerinin daha kolay ve hassas analiz yapmasına imkan tanıyan ve izole bölge veya sistem performansinı izleme imkanı sunan web tabanl1 "Su Dengesi Hesaplama Arac1" geliştirilmiştir. Su dengesi hesaplama arac1, Bakanlığın Su İdarelerinden ve Belediyelerden yıllık olarak talep ettiği hesap detayları ve raporlamaları ve su dengesinin analizinde literatürde önerilen analiz detaylarını dikkate 
almakta ve kullanıcı için hassas ve doğru analiz imkanı sunmaktadır. Benzer şekilde MNF analizinin gerçekleştirilmesi, gece yasal tüketimlerin ve belirsiz sızıntıların doğru bir şekilde hesaplanması, katsayıların doğru bir şekilde seçilmesi ve en önemlisi kullanıcıların için hassas ve doğru analiz gerçekleştirilmesi için "minimum gece debisi hesaplama aracı" geliştirilmiştir. $\mathrm{Bu}$ hesaplama aracı İdarelerde, sızıntıların yönetilmesinde, sistem verimliliğinin sağlanmasında ve sızıntı hesaplarının daha sistematik ve hassas bir şekilde yapılmasında önemli katkılar sunmaktadır. Son olarak, ILI ve UARL parametrelerinin sistematik bir şekilde hesaplanması, çıkan sonuçların yorumlanması, literatürde önerilen sınır değerlerle kıyaslanması ve böylelikle sistemin performansının değerlendirilmesi için "altyapı kaçak indeksi hesaplama aracı" geliştirilmiştir. Bu hesaplama arac1 ile İdarenin sızıntı yönetimindeki performansının izlenmesi ve buna göre en uygun yöntemin belirlenmesi mümkün olmaktadır.

\section{Teşekkür}

Bu çalışma, İnönü Üniversitesi Bilimsel Araştırma Projeleri Birimi, (İ̈̈-BAP FOA-2018-626) tarafindan desteklenmiştir. Yazarlar desteklerinden dolayı İ̈̈-BAP birimine teşekkür eder.

\section{Kaynaklar}

AWWA (American Water Works Association). (2014). Free Water Audit Software, version 5.0. https://www.awwa.org/ResourcesTools/Resource-Topics/Water-Loss-Control

Babić, B., Dukić, A. and Stanić, M. (2014). Managing water pressure for water savings in developing countries. Water SA, 40(2), 221-232. https://doi.org/10.4314/wsa.v40i2.4

Cheung, P. B., Girol, G. V., Abe, N. and Propato, M. (2010). Night flow analysis and modeling for leakage estimation in a water distribution system. In Integrating Water Systems - Proceedings of the 10th International on Computing and Control for the Water Industry, CCWI 2009.

Choi, T., Hong, M., Kim, J. and Koo, J. (2015). Efficient minimum night flow analysis using Bayesian inference. Journal of Water Supply: Research and Technology - AQUA, 64(1), 10-18. https://doi.org/10.2166/aqua.2014.166

Creaco, E., Campisano, A., Fontana, N., Marini, G., Page, P. R. and Walski, T. (2019). Real time control of water distribution networks: a state-ofthe-art review. Water Research, 161, 517-530.
Eggimann, S., Mutzner, L., Wani, O., Schneider, M. Y., Spuhler, D., Moy De Vitry, M. and Maurer, M. (2017). The potential of knowing more: a review of data-driven urban water management. Environmental Science and Technology, 51(5), 2538-2553. https://doi.org/10.1021/acs.est.6b04267

Eugine, M. (2017). Predictive leakage estimation using the cumulative minimum night flow approach. American Journal of Water Resources, 5(1), 1-4. https://doi.org/10.12691/AJWR-5-1-1

Fallis, P., Hübschen, K., Oertlé, E., Ziegler, D., Klingel, P., Knobloch, A. and Christine Laures. (2011). Guidelines for water loss reduction, 236.

Fantozzi, M., Calza, F. and Lambert, a. (2009). Experience and results achieved in introducing district metered areas (dma) and pressure management areas (PMA) at Enia Utility (Italy). Proceedings of the 5th IWA Water Loss Reduction Specialist Conference.

Farah, E. and Shahrour, I. (2017). Leakage detection using smart water system: combination of water balance and automated minimum night flow. Water Resources Management, 31, 4821-4833. https://doi.org/10.1007/s11269-017-1780-9

Farley, M. and Liemberger, R. (2005). Developing a non-revenue water reduction strategy: planning and implementing the strategy. Water Science and Technology: Water Supply., 15(1), 41-50.

Farley, M., Wyeth, G., Ghazali, Z. B. M., Istandar, A. and Singh, S. (2008). The Manager's NonRevenue Water Handbook. A Guide to Understanding Water Losses.

Farley, Malcolm. (2001). Leakage Management and Control: A Best Practice Training Manual. WHO.

Fontana, N., Giugni, M., Glielmo, L., Marini, G. and Zollo, R. (2018). Real-time control of pressure for leakage reduction in water distribution network: field experiments. Journal of Water Resources Planning and Management, 144(3). https://doi.org/10.1061/(ASCE)WR.19435452.0000887

García, V. J. and Cabrera, E. (2007). The minimum night flow method revisited. In 8th Annual Water Distribution Systems Analysis Symposium 2006. https://doi.org/10.1061/40941(247)35

Gupta, A. and Kulat, K. D. (2018). A selective literature review on leak management techniques for water distribution system. Water Resources Management, 32(10), 3247-3269. https://doi.org/10.1007/s11269-018-1985-6 
Hamilton, S., Mckenzie, R. and Seago, C. (2006). A review of performance indicators for real losses from water supply systems. Voda i Sanitarna Tehnika, 36(6), 15-24.

Jadhao, R. D., and Gupta, R. (2018). Calibration of water distribution network of the Ramnagar zone in Nagpur City using online pressure and flow data. Applied Water Science, 8, 29. https://doi.org/10.1007/s13201-018-0672-3

Kleiner, Y., Adams, B. J. and Rogers, J. S. (2001). Water distribution network renewal planning. Journal of Computing in Civil Engineering, 15(1). https://doi.org/10.1061/(ASCE)08873801(2001)15:1(15)

Lambert, A., Charalambous, B., Fantozzi, M., Kovac, J., Rizzo, A. and Galea St. John, S. (2014). 14 years experience of using 1wa best practice water balance and water loss performance indicators in Europe. Proceedings of the WaterLoss Conference 2014.

Lambert, A. O., Brown, T. G., Takizawa, M. and Weimer, D. (1999). A review of performance indicators for real losses from water supply systems. Journal of Water Supply: Research and Technology - AQUA, 48(6), 227-237. https://doi.org/10.2166/aqua.1999.0025

Liemberger, R, Brothers, K., Lambert, A., Mckenzie, R., Rizzo, A. and Waldron, T. (2007). Water loss performance indicators. Water 21, (September), $148-160$.

Liemberger, Roland. and Farley, M. (2004). developing a non-revenue water reduction strategy part 1 : investigating and assessing water losses. Proc IWA 4th World Water Congress and Exhibition 1924 September 2004 Marrakech Morocco, 110.

Lipiwattanakarn, S., Kaewsang, S., Pornprommin, A. and Wongwiset, T. (2019). Real benefits of leak repair and increasing the number of inlets to energy. Water Science\&Technology., 14:3, 714725.

Mann, E. and Frey, J. (2011). Optimized pipe renewal programs ensure cost-effective asset management. In Pipelines 2011: A Sound Conduit for Sharing Solutions - Proceedings of the Pipelines $2011 \quad$ Conference.
https://doi.org/10.1061/41187(420)5

McKenzie, R., Seago, C. and Liemberger, R. (2008). Benchmarking of losses from potable water reticulation systems - results from IWA task team. In Proceedings of Water Loss 2008 New Zealand.

Moglia, M., Burn, S. and Meddings, S. (2006). Decision support system for water pipeline renewal prioritisation. Electronic Journal of Information Technology in Construction, (11), 237-256.

Mutikanga, H. E., Sharma, S. and Vairavamoorthy, K. (2009). Water loss management in developing countries: challenges and prospects. Journal/American Water Works Association, 101(12), 57-68. https://doi.org/10.1002/j.15518833.2009.tb10010.x

Mutikanga, H. M., Sharma, S. K. and Vairavamoorthy, K. (2013). Methods and tools for managing losses in water distribution systems. Journal of Water Resources Planning and Management, 139(2), 166-174.

Nafi, A., Werey, C. and Llerena, P. (2008). Water pipe renewal using a multiobjective optimization approach. Canadian Journal of Civil Engineering, 35(1), 87-94. https://doi.org/10.1139/L07-075

Puust, R., Kapelan, Z., Savic, D. a. and Koppel, T. (2010). A review of methods for leakage management in pipe networks. Urban Water Journal, 7(1), 25-45. https://doi.org/10.1080/15730621003610878

Roshani, E. and Filion, Y. (2014). WDS leakage management through pressure control and pipes rehabilitation using an optimization approach. Procedia Engineering, 89, 21-28. https://doi.org/10.1016/j.proeng.2014.11.155

Zyoud, S. H., Kaufmann, L. G., Shaheen, H., Samhan, S. and Fuchs-Hanusch, D. (2016). A framework for water loss management in developing countries under fuzzy environment: Integration of Fuzzy AHP with Fuzzy TOPSIS. Expert Systems with Applications, 61, 86-105. https://doi.org/10.1016/j.eswa.2016.05.016 